JESTT Vol. 1 No. 7 Juli 2014

\title{
IMPLEMENTASI AKUNTABILITAS DALAM KONSEP METAFORA AMANAH DI LEMBAGA BISNIS SYARIAH \\ (STUDI KASUS : SWALAYAN PAMELLA YOGYAKARTA)
}

\author{
Rahmah Yulisa Kalbarini \\ Mahasiswa Program Studi S1 Ekonomi Islam - Fakultas Ekonomi dan Bisnis - Universitas \\ Airlangga \\ Email: rinikalbarini@yahoo.com \\ Noven Suprayogi \\ Departemen Ekonomi Syariah - Fakultas Ekonomi dan Bisnis - Universitas Airlangga \\ Email: noven2005@yahoo.com
}

\begin{abstract}
:
This study is aimed to find out accountability within Trustful metaphor concept and know the process also type of accountability in islamic business organization case study at Pamella Supermarket.

The methods of this study is qualitative approach using research study. The analyze technique is domain and taxonomy. Data is collected by interview, passive participant observation, and secondary data. The informants of this research are an assistant manager, a marketing officer, an employee and costumers of the Pamella Swalayan in Yogyakarta.

The results obtained, that the implementation of accountability with trustful metaphor concept in Pamella Supermarket based on pamella owner's concept on accountability that the purpose of life is rahmatan lil alamin that is each muslim can give a benefit to of the muslims. The realization of that concept is there will be a separation of responsibility : business fund from social fund which is managed by Pamella. From the supermarket sight, the business fund is under the responsibility of the owner and to Allah SWT. While the social fund is under the responsibility of the society by holding some social humanity program, which are reported to the society as well as to the existing interrelated departments in Yogyakarta.
\end{abstract}

Keywords: Accountability, Trustful metaphor, responsibility, business fund, social fund

\section{PENDAHULUAN}

Bisnis merupakan salah satu ragam pekerjaan yang wajib dilakukan umat muslim untuk memenuhi kebutuhan hidupnya. Allah SWT melapangkan bumi serta menyediakan berbagai fasilitas yang dapat digunakan manusia untuk mencari rezeki. Bisnis dalam Islam tidak hanya serangkaian aktivitas untuk mencari laba/keuntungan sebanyak-banyaknya, tetapi dibatasi dalam cara perolehan dan pendayagunaannya dengan aturan halal dan haram (Abdurrahman,2013:263).

Akuntabilitas secara harfiah,
dalam bahasa inggris disebut
accountability yang diartikan sebagai

keadaan untuk dipertanggungjawabkan atau dalam kata sifat disebut accountable yang diartikan sebagai tanggung jawab. Al-Qur'an dan Sunnah mendefinisikan akuntabilitas dengan apa yang benar, jujur, dan adil, apa preferensi dan prioritas masyarakat, peran serta tanggung jawab perusahaan. 
Amanah adalah sesuatu yang dipercayakan kepada orang lain untuk digunakan sebagaimana mestinya sesuai dengan keinginan yang mengamanahkan.

Lembaga bisnis yang menerapkan prinsip syariah dalam menjalankan bisnisnya adalah swalayan Pamella di Yogyakarta. Swalayan Pamella mengadakan kegiatan kemanusiaan melalui dana sosial konsumen yang diambil dari kembalian konsumen. Swalayan Pamella memberikan informasi kepada konsumen mengenai dana sosial konsumen yang mereka kelola tersebut.

\section{LANDASAN TEORI \\ PENGEMBANGAN PROPOSISI}

DAN

\section{Konsep Bisnis dalam Islam}

Setiap manusia memerlukan harta untuk memenuhi kebutuhan hidupnya sehingga manusia akan selalu berusaha memperoleh harta kekayaan itu. Usaha yang dilakukan manusia adalah dengan bekerja dan salah satu ragam pekerjaan adalah berbisnis. Allah SWT telah melapangkan bumi serta menyediakan berbagai fasilitas yang dapat digunakan manusia untuk mencari rezeki (Abdurrahman, 2013:264-265).

Bisnis dalam Islam bertujuan mencapai tiga hal utama utama yaitu: (i). Target hasil: profit-materi dan benefitnonmateri (ii). Pertumbuhan, artinya terus meningkat. (iii). Keberkahan atau keridhaan Allah.

\section{Konsep Akuntabilitas dalam Islam}

Konsep akuntabilitas dalam Islam menyatakan bahwa manusia sebagai pemegang amanah, bukan sebagai pemegang kuasa penuh yang mengatur dunia. Manusia ditunjuk sebagai "khalifah" dalam bentuk amanah dan sebagai wakil Allah SWT. Sesuai dengan firman Allah dalam Surah Al-Baqarah:30.

Surah Al-An'am ayat 165 juga menjelaskan menjelaskan manusia sebagai "khalifah" dan bagaimana konsep pertanggungjawaban ditekankan dengan perintah dari Allah SWT melalui istilah "hisab" atau perhitungan/pengadilan (accountability) di hari pembalasan. Hisab dalam arti umum berkaitan dengan kewajiban seseorang untuk account kepada Allah SWT dalam segala hal yang berkaitan dengan usaha manusia.

\section{Konsep Metafora Amanah}

Morgan (1986) dalam Triyuwono (2000:10) menyatakan bahwa metafora adalah suatu cara berpikir dan melihat yang mempengaruhi cara seseorang melakukan interpretasi dan memahami realitas sosialnya.

Amanah dalam konteks ekonomi menyatakan bahwa segala sumber daya milik Allah dan manusia adalah seseorang yang diberi amanah untuk menyebar misi sakral yang ditugaskan kepadanya. Tujuan organisasi menurut Islam adalah menyebarkan rahmat bagi semua makhluk. Tujuan itu pada hakekatnya tidak terbatas pada kehidupan dunia 
individu, tetapi juga kehidupan setelah dunia ini.

Tujuan untuk mewujudkan organisasi yang lebih humanis, emansipatoris, transedental, dan teologikal dikiaskan menjadi metafora amanah (Triyuwono,2006:216). Metafora amanah memberikan implikasi yang fundamental terhadap konsep manajemen dan akuntansi. Metafora ini diturunkan dari sebuah "aksioma" yang mengatakan bahwa pada dasarnya manusia berfungsi sebagai Khalifatullah fil ardhi (wakil Tuhan di bumi).

Simpulan metafora amanah adalah konsep yang digunakan untuk mendesain bentuk, struktur, dan manajemen organisasi dimana organisasi tersebut merupakan instrumen yang digunakan oleh khalifah untuk menjalankan tugas mulianya dimuka bumi yakni memberikan kesejahteraan (materi dan nonmateri) bagi seluruh manusia dan alam semesta.

\section{Konsep Metafora Zakat}

Zakat secara linguistik memiliki makna ganda yaitu pertumbuhan dan juga pembersihan (Siregar 1999 dalam Triyuwono 2001:29). Makna yang terkandung adalah zakat akan membawa pertumbuhaan kekayaan dan juga membawa pahala bagi yang melakukannya. Zakat pada hakikatnya adalah kewajiban finansial seorang muslim untuk membayar sebagian kekayaan bersihnya atau hasil-hasil pertanian jika kekayaannya melebihi nisab (suatu kadar tertentu sebagai bagian dari kewajiban keagamaan yang harus ditunaikan (Nursani 2000 dalam Triyuwono 2001:29).

Metafora amanah dalam bentuk operasional bisa diturunkan menjadi metafora zakat atau realitas organisasi yang dimetaforakan dengan zakat (zakat metaphorized organisational reality). Metafora ini memberikan arti bahwa organisasi bisnis orientasinya tidak lagi profit-oriented atau stockholders-oriented tetapi zakat-oriented dan environment and stakeholders-oriented (Triyuwono, 2006:352).

\section{Shari'ah Enterprise Theory}

Shari'ah Enterprise Theory merupakan penyempurnaan teori yang mendasari enterprise teory sebelumnya. Aksioma penting yang mendasari penetapan konsep Shari'ah Enterprise Theory adalah Allah sebagai sumber amanah utama dan sumber daya yang dimiliki para stakeholders. Sumber daya tersebut melekat suatu tanggungjawab dalam penggunaan, cara dan tujuan yang ditetapkan sang Pemberi Amanah. Haryadi (2010:42) menyatakan bahwa pihak yang menerima pendistribusian nilai tambah dalam teori ini diklasifikasikan menjadi dua golongan yakni direct participants dan indirect participant. Direct participants adalah pihak yang terkait langsung dengan bisnis perusahaan sedangkan indirect stakeholders adalah pihak yang tidak 
terkait langsung dengan bisnis perusahaan.

\section{Shariah Enterprise Theory}

mengajarkan bahwa hakekat kepemilikan utama berada pada kekuasaan Allah, sementara manusia hanya diberi hak untuk mengelola (khalifa fil ardhi). Manusia diharuskan mempertanggungjawabkan seluruh aktivitas kepada Allah secara vertikal, dan kemudian dijabarkan lagi dalam bentuk pertanggungjawaban secara horizontal kepada umat manusia lain serta pada lingkungan alam. Berdasarkan penjelasan tersebut penelitian ini didasarkan atas proposisi sebagai berikut:

$$
\text { Manusia sebagai khalifatullah fil }
$$

ardhi memiliki misi mulia yaitu menciptakan dan mendistribusikan kesejahteraan (materi dan nonmateri) bagi seluruh manusia dan alam semesta, untuk mempermudah tugas ini manusia dapat menciptakan organisasi (organisasi profit atau organisasi nonprofit) yang digunakan sebagai instrumen dalam mengemban tugas tersebut sehingga organisasi diharuskan mempertanggungjawabkan seluruh aktivitas kepada Allah secara vertikal, dan kemudian dijabarkan lagi dalam bentuk pertanggungjawaban secara horizontal kepada umat manusia lain serta pada lingkungan alam.

Penelitian ini memiliki kerangka teoritis sebagaimana ditunjukkan dalam gambar 2.1. Konsep metafora amanah yang merupakan obyek dari penelitian ini mempunyai konsep dasar teoritis yaitu
Shariah Enterprise Theory. Shariah Enterprise Theory ini menyatakan bahwa penerima pertanggungjawaban di dalam lembaga bisnis syariah terdiri atas dua yakni direct participant dan indirect participant. Direct participant adalah pihak-pihak yang secara langsung terlibat dalam aktivitas bisnis seperti pemilik, karyawan, investor dan karyawan perusahaan sedangkan indirect participant adalah pihak-pihak yang secara tidak langsung terlibat dalam aktivitas bisnis yakni Allah SWT, masyarakat, alam dan stakeholder lainnya.

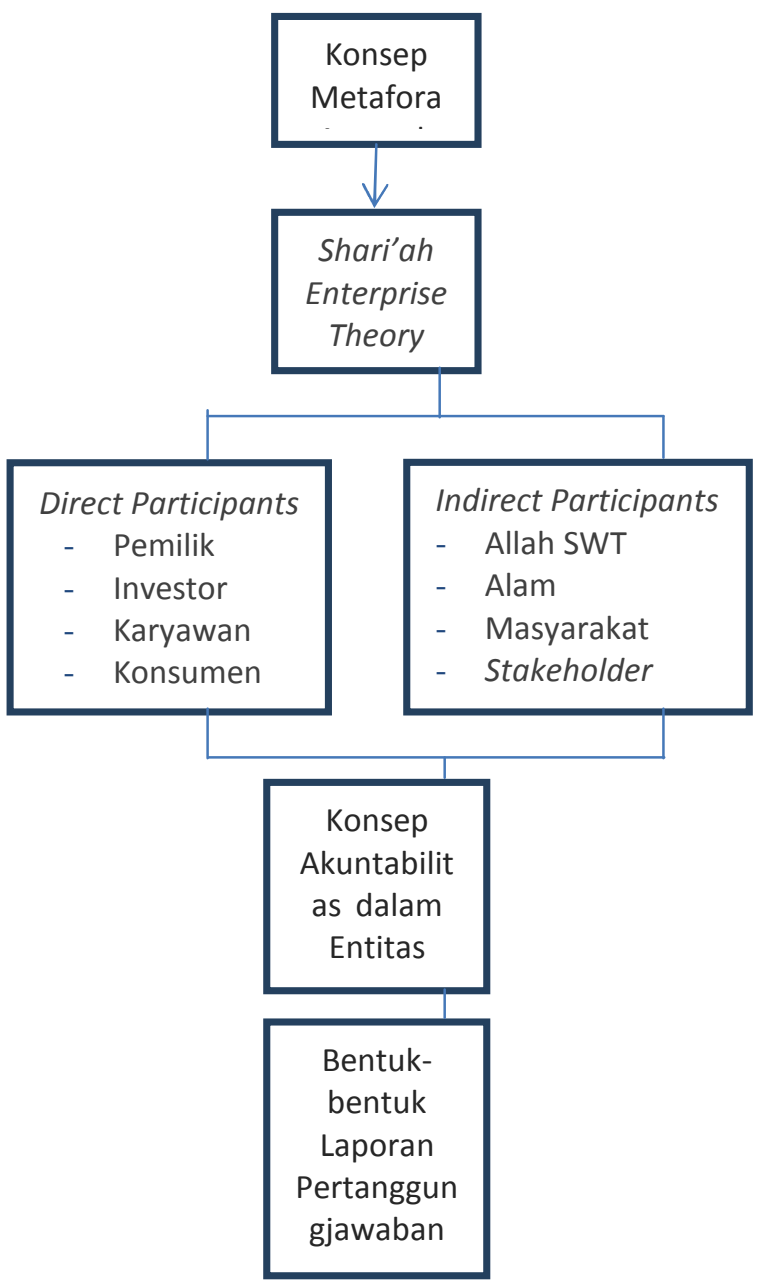

Gambar 2.1 Kerangka Teoritis 
Shariah Enterprise Theory menghasilkan konsep akuntabilitas dalam entitas bisnis syariah yang diwujudkan dalam bentuk laporan pertanggungjawaban entitas bisnis syariah. Penelitian ini untuk mengetahui bagaimana proses implementasi akuntabilitas yang dilihat dari bentukbentuk laporan pertanggungjawaban entitas bisnis syariah.

\section{METODE PENELITIAN}

\section{Pendekatan Penelitian}

Pendekatan yang digunakan dalam penelitian ini adalah pendekatan kualitatif. Jenis penelitian yang digunakan dalam skripsi ini adalah Studi Kasus. Penelitian ini dilakukan melihat berkembangnya berbagai lembaga bisnis di masyarakat yang berbasis syariah dan salah satu fenomenanya adalah swalayan pamella yang dikelola secara syari'ah dan memiliki aktivitas syariah yang dapat dipertanggungjawabkan pada publik.

\section{Jenis dan Sumber Data}

a. Data primer di dalam penelitian ini diperoleh dari hasil wawancara kepada pihak yang bertanggung jawab terhadap akuntabilitas lembaga bisnis yakni pimpinan, manajer operasional, dan manajer keuangan serta karyawan Swalayan Pamella.

b. Observasi dan dokumentasi yang berisi bentuk dan cara akuntabilitas Swalayan Pamella menjadi salah satu sumber data sekunder di dalam penelitian ini.

\section{Teknik Pengumpulan Data}

Teknik pengumpulan data yang digunakan dalam penelitian ini adalah :

a. Observasi partisipatif pasif

Peneliti datang ke subyek penelitian yaitu Swalayan Pamella tetapi tidak terlibat dalam kegiatan operasional usaha tersebut.

b. Wawancara/interview

Penelitian ini menggunakan metode wawancara terstruktur dimana peneliti telah menyiapkan instrumen penelitian berupa pertanyaan-pertanyaan tertulis. Wawancara ini ditunjukkan kepada pimpinan, manajer operasional dan manajer keuangan serta karyawan swalayan Pamella.

c. Dokumentasi dalam penelitian ini adalah contoh laporan aktivitas swalayan pamella.

Asisten Manajer Swalayan yakni Bapak Wildan merupakan key informan dalam penelitian. Bapak Wildan menjelaskan secara rinci konsep, proses dan bentuk akuntabilitas yang ada di Swalayan Pamella. Manajer Pemasaran yakni Bapak Walidi merupakan pihak yang bertanggung jawab atas seluruh aktivitas terkait dana sosial konsumen yang ada di Swalayan Pamella.

Manajer keuangan Pamella satu yakni Ibu Nani adalah pihak yang bertanggungjawab atas keuangan Swalayan Pamella satu dan berkewajiban memberikan informasi mengenai 
keuangan Swalayan Pamella satu kepada pimpinan swalayan. Karyawan swalayan pamella yakni Bapak Agus adalah pihak yang bertanggungjawab melayani konsumen swalayan. Ibu Tjoko dan Ibu Yuli adalah konsumen sekaligus masyarakat sekitar swalayan yang merasakan manfaat adanya Swalayan Pamella dan program-program yang diadakannya.

\section{Validasi Data}

Penelitian ini menggunakan dua metode validasi data yaitu.

a. Triangulasi data adalah menggabungkan beberapa data yang didapat dari wawancara kepada berbagai pihak. Triangulasi data dalam penelitian ini adalah peneliti tidak hanya melakukan wawancara kepada beberapa pihak tetapi peneliti juga melihat berbagai dokumen atau arsip yang menunjang dalam penelitian ini.

b. Triangulasi sumber adalah menggabungkan hasil wawancara antar narasumber. Triangulasi sumber dalam penelitian ini adalah peneliti melakukan wawancara kepada beberapa pihak yang berkepentingan di dalam penelitian ini. Proses triangulasi sumber dalam penelitian ini adalah peneliti melakukan wawancara kepada key informan yaitu pimpinan swalayan pamella, kemudian peneliti juga mewawancarai manajer operasional, manajer kevangan dan karyawan swalayan Pamella untuk mendukung informasi yang diberikan.

\section{Teknik Analisis Data}

Analisis data dalam penelitian ini meliputi :

a. Analisis domain

Analisis ini digunakan untuk memperoleh gambaran umum mengenai akuntabilitas di lembaga bisnis syariah. Gambaran umum meliputi konsep, proses dan bentuk akuntabilitas di Swalayan Pamella.

b. Analisis taksonomi

Analisis ini digunakan untuk memperoleh gambaran mengenai tujuan dan bentuk-bentuk akuntabilitas di Swalayan Pamella.

\section{HASIL PENELITIAN DAN PEMBAHASAN}

\section{Konsep Akuntabilitas}

Konsep akuntabilitas dalam Swalayan Pamella memiliki arti sebagai bentuk pertanggungjawaban pemilik kepada Allah dan masyarakat. Akuntabilitas juga diartikan sebagai amanah bagi lembaga bisnis syariah.

Akuntabilitas merupakan hal yang penting karena tujuan utama lembaga bisnis syariah adalah rahmatan lil alamin yaitu memberikan manfaat kepada sesama manusia.

Konsep akuntabilitas juga ditunjukkan kepada konsumen di Swalayan ini dengan cara adanya penggunaan dana sosial konsumen. Swalayan Pamella juga mengeluarkan dana zakat sebagai bentuk pertanggungjawaban kepada Allah yang disalurkan melalui lembaga zakat maupun langsung kepada masyarakat. 


\section{Proses akuntabilitas}

Proses akuntabilitas dalam Swalayan Pamella dijelaskan melalui sumber dana yang ada di swalayan tersebut. Laporan keuangan yang baik adalah laporan kevangan yang tercatat secara rapi dan sistematis sehingga pemilik Swalayan Pamella mempercayai pencatatan laporan keuangan kepada orang yang berpengalaman dan ahli dibidang keuangan serta dapat dipercaya.

Swalayan Pamella memiliki beberapa laporan keuangan sebagai bentuk pertanggungjawaban swalayan. Laporan keuangan tersebut terdiri dari jurnal, neraca, laba rugi, penyaluran dana sosisl konsumen dan penyaluran dana zakat.

\section{Bentuk-bentuk Akuntabilitas}

Bentuk akuntabilitas di swalayan ini terlihat dari cara pihak swalayan dalam memberikan informasi mengenai dana dana yang mereka kelola. Pertanggungjawaban Swalayan Pamella lainnya adalah adanya pengeluaran dana zakat sebagai bentuk pertanggungjawaban kepada Allah. Bentuk pertanggungjawabannya adalah dengan pembuatan laporan keuangan yang ditunjukkan keoada pemilik sebagai bahan evaluasi dana zakat kedepan.

Pertanggungjawaban kepada masyarakat diwujudkan dalam bentuk dana sosial konsumen. bentuk pertanggungjawaban dari dana ini adalah adanya pembuatan laporan pertanggungjawaban setiap empat bulan disertai foto-foto dokumentasi dan bukti lainnya yang diberikan kepada pihak yang berkepentingan dan masyarakat.

\section{Pembahasan Konsep Akuntabilitas}

Hasil analisis data penelitian memperlihatkan fenomena gejala umum dalam konsep akuntabilitas di Swalayan Pamella. Fenomena tersebut adalah pengertian akuntabilitas dan alasan penting adanya akuntabilitas di Swalayan Pamella.

Pengertian akuntabilitas dalam Islam telah diketahui dan diimplementasikan dengan baik oleh Swalayan Pamella. Swalayan Pamella menyatakan akuntabilitas adalah pertanggungjawaban apa yang dikelola kepada Allah.

Tujuan organisasi menurut Islam adalah menyebarkan rahmat bagi semua makhluk. Tujuan inilah yang dijadikan alasan penting adanya akuntabilitas di Swalayan Pamella. Konsep pertanggungjawaban ini juga telah diterapkan di Swalayan Pamella. Hal ini terlihat dari lingkungan dan budaya yang ada di Swalayan Pamella telah sesuai dengan lingkungan dalam Islam seperti penggunaan jilbab bagi karyawan wanita dan larangan merokok bagi karyawan laki-laki.

Amanah adalah sesuatu yang dipercayakan kepada orang lain untuk digunakan sebagaimana mestinya sesuai dengan keinginan yang mengamanahkan (Allah) dan tidak 
mengambil apa yang bukan menjadi haknya. Amanah inilah yang merupakan arti akuntabilitas menurut Ibu Nani sebagai manajer keuangan Swalayan Pamella satu.

Swalayan Pamella telah berusaha menjalankan amanah dengan sebaikbaiknya melalui adanya alokasi dana yang berasal dari konsumen dan diberikan kepada masyarakat sekitar melalui program-program yang bermanfaat dan adanya pemberian beberapa tunjangan dan gaji yang layak yang ditunjukkan kepada seluruh karyawan Swalayan Pamella. Pernyataan mengenai tunjangan karyawan.

$$
\text { Shariah Enterprise Theory }
$$

menyatakan bahwa hakekat kepemilikan utama berada pada kekuasaan Allah, sementara manusia hanya diberi hak untuk mengelola (khalifa fil ardhi). Manusia diharuskan mempertanggungjawabkan seluruh aktivitas kepada Allah secara vertikal, dan kemudian dijabarkan lagi dalam bentuk pertanggungjawaban secara horizontal kepada umat manusia lain serta pada lingkungan alam.

Shariah Enterprise Theory juga diterapkan di Swalayan Pamella. Swalayan ini mengeluarkan dana zakat sebagai bentuk pertanggungjawaban vertikal kepada Allah kemudian terdapat dana sosial konsumen sebagai bentuk pertanggungjawaban secara horizontal kepada masyarakat. Walaupun demikian, dalam bentuk pelaporan akuntansi, Swalayan Pamella belum menerapkan
Shariah Enterprise Theory yakni adanya pelaporan value added statement sebagai pemberi informasi yang lebih transparan mengenai pendistribusian nilai tambah tambah yang diciptakan perusahaan.

$$
\text { Setiap manusia sebagai }
$$

khalifatullah diberi amanat untuk mengelola kepemilikan dan otoritas di dunia ini sehingga manusia (muslim) diwajibkan untuk mengeluarkan sebagian dari harta yang dimilikinya dalam bentuk zakat untuk orang yang berhak menerima. Swalayan Pamella menyatakan bahwa zakat adalah habluminallah yang pertanggungjawabannya hanya ditunjukkan kepada Allah.

Pertanggungjawaban secara vertikal kepada Allah kemudian dijabarkan lagi dalam bentuk pertanggungjawaban secara horizontal kepada umat manusia lain serta pada lingkungan alam. Pertanggungjawaban ini sebagai bentuk tugas mulia manusia sebagai khalifah yaitu menciptakan dan mendistribusikan kesejahteraan (materi dan non materi) bagi seluruh manusia dan alam semesta. Swalayan Pamella menjalankan tugas mulia ini kepada masyarakat dengan cara membuat program dana sosial konsumen. Program ini berasal dari konsumen Swalayan Pamella dan diperuntukkan kepada konsumen dan masyarakat yang tidak mampu. Bapak Wildan menyatakan bahwa dana sosial konsumen merupakan 
bentuk pertanggungjawaban pemilik kepada Allah dan masyarakat.

Pembahasan Proses Akuntabilitas

Swalayan Pamella memiliki cara untuk mempertanggungjawabkan kegiatan operasional yang dijalankannya salah satunya adalah dengan membuat beberapa laporan keuangan guna mencatat transaksi-transaksi yang ada.

Pencatatan dimulai dari laporan setoran kasir yang berasal dari kasir-kasir yang ada di Swalayan tersebut, dilanjutkan dengan pemisahan pendapatan sebagai keuntungan dan pendapatan yang diputar kembali menjadi modal. Keuntungan yang didapat disisihkan kembali untuk operasional dan laba bersih. Laba bersih inilah yang kemudian dihitung untuk dikeluarkan zakatnya. Dana zakat yang telah dikeluarkan oleh pihak swalayan kemudian dibuat laporan penggunaannya sebagai bahan evaluasi pihak swalayan kedepan.

Dana sosial yang ada di swalayan ini dimulai dari dana yang diberikan oleh konsumen yang masuk melalui kasir sebagai dana sosial kemudian dikumpulkan dan dihitung besarnya melalui sistim komputerisasi yang ada di swalayan. Dana yang telah ada kemudian disalurkan kepada masyarakat yang membutuhkan melalui kegiatankegiatan yang bermanfaat, selanjutnya dibuatlah laporan penyaluran dana sosial konsumen yang diberikan kepada beberapa pihak seperti dinas perijinan dan dinas sosial Yogyakarta.

Swalayan Pamella sangat teliti dan cermat dalam penyaluran dana sosial konsumen, hal ini dilakukan karena dana sosial konsumen merupakan amanah yang diberikan konsumen dan harus dilaksanakan pihak swalayan dengan sebaik-baiknya. Pihak swalayan berusaha agar program dana sosial konsumen tepat sasaran dan dirasakan manfaatnya langsung oleh masyarakat yang membutuhkan.

Kesimpulan dari proses akuntabilitas di swalayan ini adalah pihak swalayan membuat laporan kevangan sesuai dengan prosedur standar laporan keuangan pada umumnya yang ditambah dengan beberapa laporan lain seperti laporan penggunaan dana zakat dan laporan penyaluran dana sosial konsumen. Swalayan Pamella juga menyeleksi pihak-pihak penerima dana sosial konsumen danzakat dengan teliti dan cermat agar dana yang diberikan tepat sasaran.

\section{Pembahasan Bentuk-bentuk Akuntabilitas}

Salah satu fenomena menarik lainnya yang ada di Swalayan ini dilihat dari cara pemilik swalayan memberikan informasi kepada konsumen mengenai dana sosial konsumen baik dari jumlah dana maupun dokumentasi kegiatan yang telah dijalankan yakni dalam bentuk poster dan spanduk yang ditempel di tiap Swalayan Pamella. Adanya poster dan spanduk ini dilakukan Pamella sebagai 
bentuk pertanggungjawaban swalayan kepada konsumen yang telah rela memberikan dananya kepada pihak swalayan melalui dana sosial konsumen yang diadakan pihak swalayan.

Namun pemilik merasa media cetak seperti poster dan spanduk kurang relevan saat ini untuk digunakan sebagai alat informasi kepada konsumen dan masyarakat sehingga pemilik swalayan berencana menggunakan media sosial dan media elektronik selain media cetak untuk memberikan informasi kepada masyarakat mengenai dana sosial konsumen. Hal ini bertujuan agar konsumen dan masyarakat luas mengetahui dengan jelas mengenai dana sosial konsumen dan penyalurannya.

\section{SIMPULAN}

Simpulan yang didapat dari penelitian ini adalah sebagai berikut :

1. Implementasi akuntabilitas dalam konsep metafora amanah di Swalayan Pamella didasarkan pada konsep akuntabilitas pemilik swalayan tentang akuntabilitas bahwa tujuan utama hidup di dunia rahmatan lil alamin yaitu setiap umat muslim diharuskan memberikan manfaat kepada sesama sebagai makhluk Allah. Perwujudan konsep tersebut dilakukan dengan pemisahan pertanggungjawaban dana bisnis dan non bisnis yang dikelola oleh pihak swalayan.
2. Pertanggungjawaban dana bisnis yang dikelola pihak swalayan dipertanggungjawabkan kepada Allah melalui dana zakat dan laporan pertanggungjawabannya dibuat oleh pemilik sebagai bahan evaluasi peningkatan target zakat kedepan. Dana non bisnis yang dikelola pihak swalayan dipertanggungjawabkan kepada masyarakat melalui berbagai kegiatan sosial kemanusiaan dan laporan pertanggungjawabannya diberikan kepada masyarakat melalui berbagai media seperti poster dan spanduk. Laporan juga diberikan kepada beberapa dinas terkait yang ada di Yogyakarta sebagai pihak yang berwenang dalam perijinan pelaksanaan kegiatan Swalayan Pamella.

\section{DAFTAR PUSTAKA}

Abdurrahman, Nana Herdiana. 2013. Manajemen Bisnis Syariah dan Kewirausahaan. Bandung: CV. Pustaka Setia.

Afifuddin dan Beni Ahmad Saebani. 2009. Metodologi Penelitian Kualitatif. Jakarta: Pustaka Setia.

Almath, muhammad faiz. 1991. 1100 Hadits Terpilih. Jakarta: Gema Insani.

Basri, Hasan dan Siti Nabiha Abdul Khalid. April 2012. Examining Accounting and Accountability Issues in Religious. Aceh International Journal of Social Sciences. Volume 1, No. 1: 24-31. 
Departemen Agama. 2002. Mushaf AlQur'an Terjemah. Jakarta: Pena Pundi Aksara.

Harahap, Sofyan syafri. 2001. Menuju Perumusan Teori Akuntansi Islam. Jakarta: PT. Pustaka Quantum.

Harahap, Sofyan syafri. 2004. Akuntansi Islam. Jakarta: PT. Bumi Aksara.

Harahap, Sofyan Syafri. 2008. Kerangka Teori \& Tujuan Akuntansi Syari'ah. Jakarta: Pustaka Quantum.

Haryadi, Bambang. 2010. Political Economy of Shariah Accounting (Membangun Teori Ekonomi Politik Akuntansi Syari'ah). Malang: Pascasarjana Universitas Brawijaya. Kholmi, masiyah. Juni 2012. Akuntabilitas dan Pembentukan Perilaku Amanah dalam Masyarakat Islam. Volume 15, No. 1: 63-72.

Kiswanto dan Hasan Mukhibad. September 2011. Analisis Budaya Islam Dan Akuntabilitas. Jurnal Dinamika Akuntansi. Volume 3, No. 2: 77-89.

Muhammad. 2002. Pengantar Akuntansi Syari'ah. Jakarta: Salemba Empat. Mulawarman, Aji dedi.2009. Akuntansi Syariah (Teori, konsep, dan laporan keuangan). Jakarta: E-Publishing Company.

Noor, Ali Fikri.2014. Serial Akhlak Muslim: Amanah. Jakarta: e-book.

Permatasari, Nurhidayah Chairany dan Nurul Hasanah Uswati Dewi. July 2011. Pandangan Pemilik Badan
Usaha Islam Terhadap Akuntabilitas Dan Moralitas. The Indonesian Accounting Review. Volume 1, No. 2: 135 - 144.

Priansa Donni Juni dan Buchari Alma. 2009. Manajemen Bisnis Syari'ah. Bandung: Alfabeta.

Shihab,M. Quraisy. 2009. Tafsir Al-Mishbah Pesan, Kesan, dan Keserasian AlQur'an. Jakarta: Lentera Hati.

Soetedjo, Soegeng. 2009. Pembahasan Pokok-pokok Pikiran Teori Akuntansi Vernon Kam. Surabaya: Airlangga University Press.

Sugiyono. 2012. Memahami Penelitian Kualitatif. Bandung. Alfabeta.

Tampubolon, Manahatan P. 2008. Perilaku Keorganisasian Jorganizing Behavior) Perspektif Organisasi Bisnis. Bogor: Penerbit Ghalia Indonesia.

Triyuwono, Iwan dan Moh Mashudi. 2001. Akuntansi Syari'ah (Memformulasikan Konsep Laba dalam Konteks Metafora Zakat). Jakarta: Salemba Empat.

Triyuwono, Iwan. 2000. Organisasi dan Akuntansi Syari'ah. Yogyakarta: LkiS.

Triyuwono, Iwan. 2006. Akuntansi Syari'ah (Perspektif, Metodologi, dan Teori) edisi II. Jakarta: PT. Rajagrafindo Persada.

(www.suratpembaca.detik.com tanggal 6 november 2013 diakses pada tanggal 6 Juli 2014). 
JESTT Vol. 1 No. 7 Juli 2014

(www.pamellagroup.blogspot.com)

pukul 20.12.

Diakses tanggal 4 februari 2013 